REsumo

$O$ artigo discute questões relacionadas à flexibilidade do enquadre (setting) no Acompanhamento Terapêutico (AT). Para tal, traz uma revisão da técnica analitica para Freud, no que se refere à abstinência psicanalítica e Ferenczi, no que se refere à elasticidade da técnica. Discute o que alguns psicanalistas pós-freudianos entendem por enquadre analítico para chegar, enfim, à narrativa do fragmento clinico de um encontro entre a autora e sua paciente. Os desdobramentos da revisão $e$ da narrativa são os de aprofundarem uma reflexão sobre a criação e manutenção de um enquadre na modalidade clinica do AT.

Descritores: Psicanálise; Acompanbamento Terapêutico; enquadre.

\section{CONSIDERAÇÕES SOBRE O ENQUADRE NA CLIINICA DO AT}

\author{
Cristiana Kehdi Gerab \\ Manoel Tosta Berlinck
}

E ste artigo pretende, a partir de uma revisão da técnica psicanalítica e da narrativa de um fragmento clínico, abrir questionamentos relacionados à flexibilidade do setting ${ }^{1}$ na situação do Acompanhamento Terapêutico (AT). A partir desta clínica singular, clínica em movimento por definição, podese trazer elementos para se pensar em um movimento de abertura da clínica em casos de difícil manejo.

A palavra flexibilidade nos traz um sentido interessante. O que significa um trabalho clínico estar fundamentado em um setting flexível? Um setting clínico flexível deixa a nós, terapeutas, em uma situação de desproteção? A proposta aqui é fazer pensar nos elementos que compõem o setting para sustentar a hipótese de que a flexibilidade pode ser um deles.

A questão do setting pode ser amplamente discutida se partirmos da clínica do AT, já que é uma

- Mestre pelo Programa de Estudos Pós-Graduados em Psicologia Clínica da Pontifícia Universidade de São Paulo (PUC-SP).

- Sociólogo, psicanalista, Professor do Programa de Estudos Pós-Graduados em Psicologia Clínica da Pontifícia Universidade Católica de São Paulo (PUC-SP). 
clínica que traz em si uma singularidade: sustenta-se na proposta de movimento espacial. Para uma breve introdução ao AT, caberia uma definição de como, quando e porque funciona esta modalidade de atendimento. Está em geral destinada aos casos difíceis, psicoses e neuroses graves, quando o tratamento proposto em uma análise, por meio da palavra, não é suficiente para a melhora do quadro. Um acompanhante é convocado para a tentativa de fazer laço ao paciente que não sai de casa, não sai da instituição de tratamento, tem dificuldade de circular e fazer vínculos com o mundo, tendendo ao isolamento. O acompanhamento é, portanto, uma clínica que articula redes, dispositivo que foge da rigidez da instituição, da ortodoxia analítica. Palombini (2004, p. 78), ao tratar do AT na rede pública, descreve-o como uma clínica em ato, onde "o setting é a cidade: a rua, a praça, a casa, o bar. Uma clínica em que a palavra e também o corpo, os gestos, as atitudes contam."

Nessa citação, Palombini coloca que um elemento importante em jogo no AT é a circulação pelo espaço físico, fazendo, entretanto, um apontamento em relação ao ato e corpo do terapeuta. Abarca, assim, a questão da posição do analista no que concerne às regras e normas adotadas para $\mathrm{O}$ andamento do processo terapêutico, outro elemento do setting. O termo flexibilidade articula-se tanto à ideia de circulação quando à ideia do corpo como setting.
Propõe-se, desta maneira, passagens por autores que discorram sobre o setting na psicanálise para se ampliar a discussão juntamente à narrativa do fragmento clínico.

Green (2008) relembra-nos que a introdução do termo enquadre foi dada por Bleger, na Argentina, e Winnicott, na Inglaterra. Enquanto Bleger o associou à simbiose, tendo pouca repercussão de suas ideias fora da América Latina, Winnicott o traz definido da seguinte maneira: "Conjunto das condições de possibilidade requeridas para o exercício da psicanálise. Isso compreende as disposições materiais que regulam as relações entre analisando e analista" (p. 53).

Green divide o enquadre, ou a montagem, termo que ele propõe, entre enquadre material (o contrato analítico) e a regra fundamental. Enquanto o enquadre material diz respeito ao contrato analítico, ou seja, pagamento, duração das sessões e estabelecimento das férias, a regra fundamental diz respeito ao processo analítico. Green fala em "estojo e matriz ativa" enquanto termos que também designam essa divisão do enquadre em duas partes: o material (tempo e espaço - o estojo) e a virtual, ou, como ele mesmo denomina, o "enquadre interno".

O estojo, ou o contrato, que abarca as condições do espaço e do tempo, é fundamental para tornar possível o processo. Mas há um enquadre, na montagem de que fala Green, que permanece invisível. Virtual. Diz res- 
peito à regra fundamental, que, a depender do analista, pode ou não ser enunciada como parte do contrato. Green (2008) define-a como a demanda do analista de que o paciente diga tudo, inclusive o que parece mais absurdo, e que nada faça além deste exercício de solilóquio em voz alta. Sua importância, segundo Green, é a de que a regra desempenha um papel de terceiro, lei acima das duas partes.

Quando Green fala de um exercício de solilóquio em voz alta, faz um apontamento importante: o endereçamento dessa fala se faz a um alguém invisível, que alterna entre presença e ausência. Nesse sentido, sublinha aquilo que não se materializa no enquadre e que, por ser estabelecido de uma forma materialmente adequada à situação analítica (o uso do divã, os silêncios e falas alternadas do analista, a associação livre), torna possível uma atividade.

Pierre Fédida (1991), autor que propõe trabalhar com a idéia de materialidade e de virtualidade do enquadre, define a situação analítica como aquela que acontece quando um enquadre seja provido de condições favoráveis para que se engendre um trabalho analítico.

a situação psicanalítica não é materializável e, no entanto, de fato, ela é materializada no que chamamos lugar das sessões, a disposição espacial do analista e do analisando, a existência de um horário regular, o pagamento dos honorários, etc. Essa materialização não é indiferente: ela institui a condição ética de um enquadre. (Fédida, 1991, p. 127)

Vale pensarmos a virtualidade do enquadre a partir do que Fédida entende por lugar: topos (lugar no espaço, posição, ponto de partida referente a qualquer matéria). O autor diz que o analista ocupa o lugar do ausente: estar presente em negativo, sustentar o vazio de uma não-resposta. Fédida chama o interlocutor na situação psicanalítica de uma pessoa-ninguém. Nesse lugar, o analista poderia permitir o tempo de uma elaboração, que o relato do paciente ganhe uma figuração pela linguagem, o que lhe permite dizer que não é o enquadre que faz a análise. Lugar e enquadre, para Fédida, são termos que designam diferentes significados.

Bleger (1977, p. 310), também disposto a teorizar o enquadre, define-o como aquilo que diz respeito às constantes de um fenômeno, método ou técnica. Tais constantes incluem: "o papel do analista, o conjunto de fatores espaciais e temporais e a técnica (honorários e horários)".

Assim, enfatiza também duas situações distintas e complementares na experiência clínica: o processo (ou a situação psicanalítica) 


\section{Artigo}

e o não-processo (o setting). Se o processo engloba as variáveis que compõem o tratamento, o enquadramento do processo (como ele denomina) é o que sustenta a possibilidade de ocorrência e manejo dessas variáveis. Ou seja, o setting psicanalítico é tido como uma base de sustentação do tratamento.

Bleger (1977, p. 312) define o enquadramento como uma instituição, que por sua vez é definida como o conjunto das normas, das regras e das atividades agrupadas em torno dos valores e das funções sociais. "As instituições funcionam sempre como limites do esquema corporal e núcleo básico da identidade".

O autor traz a noção de não ego: aquilo que o sujeito ainda não percebeu que pode faltar, as relações estáveis e imobilizadas. Na psicose, o não ego é aquilo a que o paciente se atém para existir. O não ego é imóvel, pertence ao campo das pulsões não metabolizadas, da simbiose e da compulsão à repetição. Tais forças, clivadas e depositadas na parte imóvel do enquadre ganhariam visibilidade caso o setting se rompesse. Em outras palavras, o que Bleger quer transmitir é que o enquadramento dá conta da pulsão de morte predominante no tratamento. Ele a contém e permite que o processo ocorra. Segundo a concepção deste autor, para que haja movimento, algo deve estar imóvel. O nãoego, assim como o setting, é a base para que o ego possa vir a se organizar quando vivencia experiências de frus- 
tração. É a partir da existência do nãoego que o ego pode se movimentar.

"A simbiose com a mãe permite à criança o desenvolvimento de seu ego; o enquadramento tem a mesma função: serve de sustentação de marco, mas só chegamos a vê-lo - por ora - quando muda ou se rompe." (Bleger, 1977, p. 315)

Retornemos às considerações sobre o setting no AT. Se suas condições de materialização são outras, poderíamos pensá-lo fazendo uma alusão ao corpo, já que, em ultima instância, é o corpo do terapeuta ao lado do paciente que funciona como uma constante. Podemos dizer que haveria na situação do AT um corpo como setting. Esta é uma ideia bastante difundida nas teorizações sobre o AT: a do corpo como setting, o corpo do terapeuta como palco de uma cena transferencial. A partir disso, pensa-se aqui que o setting no AT não se trataria tanto do espaço onde se dá a cena, mas da posição adotada pelo terapeuta de como abrigar em si o espaço e o tempo da dupla at-acompanhado.

Como escreve Coelho Junior (2008, p. 99),

a prática analítica é pensada a partir de um setting móvel e sensível, poroso ao outro e ao mundo, morada da percepção e das possibilidades de contato que tem o analista. Este setting é o corpo ... e sua porosidade frente aos seus afetos e aos do paciente.

Em outras palavras, entende a flexibilidade do setting enquanto disponibilidade do analista para ser usa- do ou influenciado pelo paciente, oferecendo seu corpo no polo oposto da defesa paranoica.

Ainda Coelho Junior (2008, p. 100) ao trazer esta questão do corpo como setting, explica que, justamente quando há uma ruptura do setting, o corpo do analista é atacado já que é com o corpo que se é penetrado por introjeções e que se realizam projeções. O rompimento do setting traria à tona a carga tanática presente naquele encontro, como também formulou Bleger (1977).

Não se pretende aqui falar do corpo em si, mas da abertura que a ideia do corpo como setting pode trazer em termos de concepções técnicas. Também Green (2008, p. 57), alertando para o fato de que não é só da abertura do analista às produções do paciente que se trata a disponibilidade, afirma: "trata-se da disponibilidade e receptividade às produções vindas do próprio inconsciente do analista".

Há que se fazer a seguinte pergunta: em se tratando do corpo enquanto aquele que guardaria o enquadre no AT, como manter-se disponível, poroso ao que surge de inesperado sem que se entre em uma posição defensiva? Figueiredo (2008) fala de reserva enquanto um conceito que ajude a pensar na posição do analista. Reserva é adotada por ele enquanto o outro polo do que ele chama implicaşão do analista. Refere-se à capacidade e posição ética que o analista deve ter de estar presente com certa 
ausência, em uma espécie de "implicação reservada".

O termo reserva demanda um retorno a Freud. Em seus textos sobre a técnica psicanalítica ${ }^{2}$, ele esclarece as regras clássicas que a compõem. É função do analista levar o paciente a se comprometer com a regra fundamental: a associação livre. Nas palavras de Berlinck (2008, pp. 260-261), “a regra fundamental compromete analisando e analista com a livre associação em prejuízo de qualquer forma de censura". O analista, por sua vez, estaria equipado de atenção equiflutuante que, nas palavras do mesmo autor, "recoloca o compromisso do analista com seu próprio trabalho analítico, além de enlaçá-lo com o espírito de curiosidade que o leva a deixar que se transforme continuamente o que pensa".

Vale frisar o pano de fundo que constitui o trabalho prático proposto por Freud: esboça-nos um analista preocupado em manter-se zeloso, em frustrar o paciente de sua necessidade e gratificações amorosas, ou de sua exigência de que $o$ analista lhe dite regras sobre como deve conduzir sua vida. $\mathrm{O}$ analista precisa ser abstinente e supor um saber irrespondível. Freud propõe a abstinência justamente a serviço da investigação das raízes inconscientes que sustentam a transferência.

É, portanto, tão desastroso para a análise que o anseio da paciente por amor seja satisfeito, quanto que seja suprimido. $\mathrm{O}$ caminho que o analista deve seguir não é nenhum destes; é um caminho para o qual não existe modelo na vida real. Ele tem de tomar cuidado para 
não se afastar do amor transferencial, repeli-lo ou torná-lo desagradável para a paciente; mas deve, de modo igualmente resoluto, recusar-lhe qualquer retribuição. (Freud, 1915/2006, p. 184)

O que parece estar em jogo aqui para Freud não é tanto o amor como uma abstração, como afeto próprio do paciente que é desencadeado na análise, mas a participação do desejo do analista nesse processo. O "firme domínio do amor transferencial" soa como paradoxal nesse texto, já que ele pode tanto afirmar um manejo técnico quanto uma formulação teórica resistencial à ideia de que o desejo do analista precisa ser integrado à formulação da teoria sobre a transferência.

Sándor Ferenczi, por sua vez, é um psicanalista voltado para o trabalho prático, "apaixonado pelas condições práticas do manejo clínico da técnica na sua vocação de ser uma técnica terapêutica" (Fédida, 1988, p. 99).

É fundamental que Ferenczi seja citado, psicanalista contemporâneo a Freud que se dispôs a traçar uma espécie de "metapsicologia da técnica". Desde o artigo intitulado "Prolongamentos da técnica ativa em psicanálise" (1912/1987) até sua conferência denominada "Elasticidade da técnica psicanalítica" (1927/1987), são abordados os temas da atividade do analista frente ao paciente e do uso da segunda regra fundamental: quem quer analisar os outros deve, em primeiro lugar, ser ele próprio analisado - o que, pela primeira vez na história da psicanálise, evidencia a vulnerabilidade psíquica do terapeuta.

A técnica ativa foi proposta por Ferenczi (1912/1987), a princípio, para certos casos de histeria de angústia nas quais haveria sintomas fóbicos. Ele propõe a utilização dessa técnica esperando que certas resistências, certos pontos mortos da análise desses pacientes sejam superados com maior rapidez. A técnica ativa consistiria, primeiramente, em incitar o paciente a realizar atos tidos por ele como desprazerosos para, em seguida, após tais atos terem sido tomados pela consciência como fontes de prazer que estariam recalcadas, interditá-los. Ferenczi cita o caso de uma paciente com quem utilizou a técnica ativa:

As injunções tiveram por conseqüência torná-la plenamente consciente de certos impulsos, até então recalcados ou que se apresentavam sob uma forma rudimentar irreconhecível, e finalmente de tomar consciência deles enquanto representações que lhe eram agradáveis, enquanto moções de desejos. (Ferenczi, 1912/1987, p. 70) 
Ferenczi, nesse texto, propõe uma inovação da técnica como uma tentativa de lidar com as resistências do paciente e acelerar o tratamento. Somente em determinada circunstância ele aconselha a técnica ativa: onde houver uma prolongada paralisação do conjunto de associações do paciente. Admite, depois, que essa técnica é contra indicada em alguns casos, e igualmente para analistas muito jovens. Observou que a técnica indiscutivelmente conduzia a uma reativação das experiências traumáticas da infância na situação analítica, mas nem sempre essa reativação era seguida de uma resolução da repetição, e sim de um aumento da tensão, podendo ocorrer, portanto, uma intensificação das resistências através do uso da atividade pelo analista. Evolui, assim, para a ideia da "elasticidade do analista". Em 1927 escreve o artigo sobre a elasticidade, propondo por elasticidade a técnica da tolerância e da indulgência.

Adquiri a convicção de que é uma questão de tato psicológico saber quando e como se comunica algo ao analisando, quando se pode declarar que o material fornecido é suficiente para tirar conclusões; de que forma deve a comunicação, num determinado caso, ser feita; como se pode reagir a uma reação inesperada ou desconcertante do paciente; quando devemo-nos calar e esperar outras associações e, em que momento o silêncio é uma tortura inútil para o paciente. (Ferenczi, 1927/ 1987c, p. 35)

Ferenczi propõe que a capacidade de tato e empatia possam ser tidas como técnica, mas que para ele parece só ser possível quando o analista em questão estiver flexível consigo mesmo, ou seja, devidamente a par de seus próprios limites. Talvez pudéssemos extrair da segunda regra fundamental da psicanálise a seguinte ideia: "a compreensão que o analista tem do que seria o setting psicanalítico se arraiga, fundamentalmente, em sua própria experiência como analisando" (De Deus, 2007, p. 98)

Ferenczi traz as bases do conceito de contratransferência, abordada por ele não como algo que dificultaria a análise, mas, ao contrário, como a própria técnica a ser empregada. Ferenczi formulava sua técnica com base em sua vivência clínica, de forma a considerar, como explica Berlinck (2008, p. 281), que "qualquer sucesso deve ser compreendido como uma interação da transferência do paciente, isto é, de sua compulsão à repetição com a contratransferência do analista, ou seja, sua técnica". Seria através das constantes inovações da técnica que ele poderia lidar com as repetições quase inalteráveis que apresentavam seus pacientes na relação transferencial. Do saber dosar a simpatia exercitando um rígido domínio da contratransferência, Ferenczi passa a propor o tato analítico (faculdade de sentir com) e a empatia. Tais manejos técnicos devem ser despojados de seu caráter místico, como ele bem situa, alertando que seriam possíveis ser exercidos graças, prioritariamente, à "análise do analista". Eis a 
importância da "equação pessoal do analista", que lhe permitirá ser aquele que pode sentir com seu paciente (em um nível pré-consciente) e avaliar a situação analítica à distância. Eis aí o que Ferenczi quer nos fazer entender por analista elástico.

A partir deste apanhado de teorizações sobre o setting e a técnica psicanalítica, vale pensarmos a técnica no AT a partir de um fragmento clínico que faz pensar a questão da flexibilidade do setting e elasticidade da técnica. Segue, então, o relato de um acompanhamento terapêutico realizado com a paciente a que chamo de Miriam. Na época, contava com 44 anos, fazia tratamento em um Centro de Atenção Psicossocial (CAPS) da cidade de São Paulo e era acompanhada por mim há cerca de dois anos.

\section{Fragmento clínico (Telepatia $^{3}$ )}

Praticamente uma constante entre as nossas cotidianas saídas, o carro. Meio de transporte entre sua casa e o resto do mundo. Entre seu ensimesmamento e a possibilidade de uma interlocutora, de um vínculo.

No carro, o silêncio. O que significava aquele silêncio, ela que andava tão falante por aqueles dias? Estávamos indo a uma exposição que nem mais sabíamos se ainda estava aberta para visitação. Ela não havido cumprido o combinado comigo de esco-

96 Estilos da Clínica, 2012, 17(1), 88-105 
lher algo e certificar-se de que estaria em exibição (era sempre eu quem estava organizando nossas saídas, por isso há algumas semanas combinamos que ela o fizesse). Diante disso, resolvemos então sair ao acaso, apostando que haveria certa exposição no lugar onde habitualmente íamos.

$\mathrm{O}$ acaso suportava uma espontaneidade, uma confiança no vínculo, um risco em poder se frustrar, em poder deparar-se com uma ausência. De certa forma, parecia-me interessante ver até que ponto ela chegaria dentro de sua possibilidade de movimentar-se frente ao acaso, ao possível risco de uma expectativa não se validar. Aqui já se esboça uma primeira ideia de setting neste AT: a segurança do auto-móvel enquanto meio de transporte, do dia e horário combinado para o encontro. O carro servia como uma constante neste AT, um símbolo de nossa possibilidade tanto de circulação como de contorno e proteção.

Miriam continuava em silêncio, no carro, enquanto eu me absorvia em pensamentos, sem saber como colocá-los em cena. Compartilhávamos o silêncio, cada uma em seu próprio imaginário. Faço então a pergunta-chave: por que está tão quieta?

"Telepatia. Estou me comunicando com você por telepatia", dizia ela.

Surpresa com seu motivo, por um momento sinto-me impotente por não dispor de sua incrível capacidade telepática. Digo a ela que não posso acompanhá-la nessa comunicação. Ela ri (há aqui um movimento em direção à alteridade) e então se apressa a falar, sua fala despedaçada de sempre, sem pontuações, sua fala delirante misturada com os fatos dos dias próximos.

Conta-me que me viu na rua. Que tem me visto e falado comigo por telepatia. Diz que Deus tem sugerido a ela que converse comigo, que eu posso ajudá-la. Como eu deveria suportar esse lugar? Ser uma enviada de Deus? Como me reservar diante de uma fala como essa, sem me colocar em uma posição defensiva?

Esta distinção deve ser feita com cuidado, já que uma presença reservada significa buscar, como escreve Figueiredo (2008, p. 27), "uma maior possibilidade de trânsito intrapsíquico, o que é condição para os ganhos na luta contra a repressão e contra cisões e dissociações". Por outro lado, se há no terapeuta uma necessidade defensiva devido à invasão de certos conteúdos do paciente, e dessa forma ele atue tentando controlar ou subjugar um saber à situação que se esboça, fecha-se o campo das comunicações.

Feitas essas pontuações, continuo meu relato clínico. 
Chegamos então ao lugar almejado, Museu de Arte Contemporânea da Universidade de São Paulo - USP. As portas fechadas já nos informavam que não havia nada acontecendo ali. O segurança nos diz que a próxima exposição está em fase de montagem. Ali ainda não havia nada para ver. Vazio.

Ela me olha com ar de frustração, diz que quer ir para casa. Permaneço ali parada por um tempo, tentando minimamente sustentar o vazio e a escolha (minha e dela) de sair ao acaso. Pergunto, com uma entonação forte: voltar para casa? Aquele momento me parecia crucial: havia uma quebra na repetição. Se sempre íamos a exposições de arte e nesse dia a exposição que supúnhamos estar acontecendo não estava lá, o que poderíamos fazer juntas? Retomei que o que ela mais andava me pedindo era que saíssemos de sua casa. Por que voltar para lá? Dispúnhamos ainda de uma hora de acompanhamento (aqui é clara a minha referência ao "estojo" de que fala Green, 2008). Ela então se questiona: mas o que vamos fazer então?

Num momento de quebra da repetição, calcamo-nos no setting para avistar um direcionamento da situação. Mas pergunto: o que é o setting aqui? A USP? Meu carro? Meu corpo? Talvez fosse necessário que o mapeássemos, juntas.

De fato, encontramos um mapa, Mapa das artes da USP, que expunha tudo o que estava acontecendo em matéria de artes pela universidade. Guia concreto, mapa do território. Ela 
se interessa pela semana das artes que estava acontecendo na Faculdade de Engenharia. Pergunto a ela o porquê desse interesse, e ela me conta algo de que eu havia esquecido: tinha estudado engenharia quando moça. Eu nunca soube ao certo se ela realmente havia estudado engenharia; outras vezes já me tinha dito que estudara Letras. $\mathrm{Na}$ verdade, talvez ela não tivesse cursado nenhuma faculdade, pois sei que foi nesse momento de sua vida que o surto psicótico aconteceu e ela se isolou em casa. Essa época de sua vida parece um grande buraco-negro, difícil de ser remontada. Ninguém de sua família se dispôs a me contar. Acredito em sua fala e na possibilidade dessa "verdade" - seja ela real, acontecida em algum tempo cronológico, seja um delírio, representante da memória anacrônica - esboçar qualquer desejo possível de ser nomeado.

Tomamos a direção por ela escolhida rumo à Escola Politécnica, para descobrir do que se tratava a semana de artes da Engenharia. Durante o caminho ela me conta, curiosamente em uma fala mais conectada e linear, que gostaria de ter sido engenheira química, que já havia trabalhado em uma fábrica, como seu pai. Vão surgindo conteúdos de sua história (processo analítico). Em seguida vai adentrando na problemática com o pai, que parece acompanhála incessantemente. Diz que nunca conseguiu ser nada por causa dele; ele roubou aquilo que lhe pertencia. Quando pergunto o que foi exatamente que ele roubou, ela se confunde, e entra em um discurso mais fragmentado, fazendo referências aos maridos, às amantes de seus maridos, às amantes de seu pai, a uma tia vulgar cuja voz ela imita, em tom de deboche. Eu, mergulhada em atenção flutuante, tentando prestar atenção no caminho para a Poli (que eu não conhecia), escutar o que fazia sentido enquanto concretamente íamos para onde seu desejo pareceu apontar, estaciono o carro. Neste momento há de minha parte uma total implicação.

Não pretendo adentrar-me na sua fala em si, mas na situação em que estávamos, isto é, nas possíveis afetações que esta situação poderia produzir em mim e nela. Durante o passeio, Miriam pareceu um pouco deslocada, olhando as salas de aula, a movimentação estudantil. Parecendo angustiada, agita-se, vai ao banheiro algumas vezes. Sinto-me mergulhada em um enigma: será que estar ali produzia muita angústia nela? Como ajudá-la a sustentar o desejo de estar ali? Suponho que seu imaginário naquele momento confrontava-se com o real vivenciado. As certezas de seu delírio competiam 
com a concretude de uma faculdade de engenharia: nada mais certo do que o concreto.

Figueiredo (2008, p. 29) explica que "manter-se em reserva é para o analista, muitas vezes, a maneira de suportar estar em situações difíceis de discriminar, situações em que as autorias e origens dos sentimentos, desejos e até necessidades perdem seus limites individuais".

Vale aqui retomar o tema da contratransferência. Fédida (1988, p. 79) concebe a "contratransferência como dispositivo econômico que permite ao analista poupar-se de experiências que não deve viver no lugar de seu paciente e muito menos por ele". A contratransferência, como também abordada em Ferenczi, articula-se com a posição de reserva. Enquanto conceito psicanalítico ajuda-nos a pensar algumas experiências afetivas intensas. Fédida propõe a ligação entre o que ele chama de contratransferência e o enquadre do tratamento. $\mathrm{O}$ efeito contratransferencial é aqui o de uma desorientação - que é diferente de uma confusão, pois se toma por desorientação neste artigo um afeito que se ajusta ao enquadre do tratamento. $\mathrm{Na}$ citação acima, podemos ter clara a relação entre a contratransferência e o enquadre do tratamento. Ou seja, haveria certa maneira de fazer uso da contratransferência, condizente com o enquadre, levando o terapeuta a não se confundir como real destinatário da proposta do paciente a uma relação dual. 
Tentei ficar ali com ela, olhar a exposição, os cartazes pregados nos murais. Um moço nos chama para conhecer a oficina de música. Ela quer ir, mas só um pouco; percebo nela um ligeiro cansaço. Vou me sentindo também tomada pelo seu cansaço (contratransferência?), e quase instantaneamente trocamos olhares que exprimiam nossa vontade de ir embora.

Sentia-me confusa, sem saber o que dizer sobre a ida à faculdade de engenharia com ela, como se houvesse acontecido algo para além do possível naquele momento. Ir até a faculdade de engenharia foi excessivo para ela? Eu havia sido demasiadamente ativa?

Voltando para o carro, dou-me conta de que não fazia nenhuma ideia de onde ele estava. O estacionamento era enorme, e os pontos de referência escassos. Não conseguia me lembrar do caminho que havíamos feito desde o carro até a exposição. Só podia me lembrar de que havia um muro cinza. Perguntava a ela, que também dizia não saber. Poderia aqui falar de uma quebra do setting?

Perdidas em um mar de carros, andávamos em errância. Minhas esperanças de encontrá-lo iam cada vez mais se esvaindo, e ela, expressando certa puerilidade, divertia-se com aquele andar desnorteado. Tantos carros pretos, tantos muros cinza, tanto asfalto, o sol do meio-dia flamejava. Tudo era igual, não havia marcas que diferenciassem nosso caminhar. Fui sendo tomada por certo nervosismo, em um momento acreditei piamente que ficaríamos ali para sempre. Seria este o sinistro experienciado pelo psicótico? Um andar sem referências, um mar de significantes que não faziam marcas que diferenciassem nem afetos, nem instantes, tudo um emaranhado só. Excesso de carros. Nenhum espaço vazio.

A hora do término do AT já havia chegado; agora, o tempo que passava era simplesmente tempo que passava. Ter um relógio não fazia mais diferença. Cesso meu caminhar, quase pedindo trégua. Digo a ela que não sei o que fazer. Miriam, então, pede calmamente para que eu pegue minha chave e tente apontar para todos os lados, atenta ao barulho que faria ao destravar. Descrente, fiz o que ela disse.

O barulho da trava, quase ao nosso lado, pareceu um milagre! De volta ao familiar, eu ria aliviada. Ela ria de mim. Disse que nunca tinha me visto tão nervosa. Que eu estava "perdendo a cabeça". Sua lucidez foi fundamental para mim.

$\mathrm{Na}$ volta, um silêncio inicial. Outro silêncio: um silêncio compartilhado e em fase de metabolização. O que havia se passado ali? 
Comunicação inconsciente? Uma reinstalação do setting analítico pela própria paciente a partir da desorientação da terapeuta?

\section{Considerações finais}

Os autores abordados para o desenvolvimento deste artigo são aqueles que têm em comum a disposição para fazer reflexões, elaborações e comentários sobre o setting analítico. Autores que dimensionam a importância do corpo, do tempo e do espaço. Da comunicação pelos afetos. Da reinvenção de uma forma de cuidado. Buscar critérios nesses autores para se falar de uma psicanálise complica$d a$, isto é, exercício da psicanálise fora de seu enquadre clássico, é buscar orientação para algo novo. O complicado remete a uma constante interferência de terceiros elementos concretos, vivos. No AT, em linhas gerais, esses terceiros constituem "a cidade". Da mesma maneira que ela interfere de forma a causar certa desorganização na dupla, ela é também parte dessa dupla e precisa ser integrada à situação clínica. Eis a inovação que o acompanhamento terapêutico traz para a clínica: a cidade não é o enquadre, mas é onde o enquadre se presentifica. Esta inovação acrescenta material para se pensar na clínica, nesse caso a clínica das psicoses, seja em termos de efeito do tratamento quanto em termos técnicos e metapsico-

102 Estilos da Clínica, 2012, 17(1), 88-105 
lógicos. A clínica do AT é de extrema potência, já que acentua os elementos constitutivos do enquadre, como em uma lente de aumento, e os coloca à prova

Nesse sentido, é interessante concluir resgatando a ideia inicial de flexibilidade e circulação. É possível entender que a circulação, o movimento pela cidade com o paciente é o que se sobressalta na clínica do AT, constitui seu diferencial, o que de fato a faz funcionar. Ao longo do artigo, esta concepção vai sendo questionada, e a partir da inclusão do fragmento clínico é possível concluir que a circulação, por si só, não garante o movimento. É necessária uma posição de clínico, um enquadre interno como diria Green (2008), manter algo imóvel para poder haver movimento, como coloca Bleger. Uma escuta atenta ao que trazia o paciente, aos afetos que permeiam o encontro, àquilo que contamina e, principalmente, aos próprios limites do terapeuta (que alude à segunda regra fundamental estabelecida por Ferenczi, 1912/1987). Por limites do terapeuta, entende-se capacidade de abstinência (não resolver prontamente o enigma trazido pelo paciente) e a abertura ao que se transmite inconscientemente e se manifesta como contratransferência - no caso, o efeito de desorientação. Disto é que se faz a clínica, e a circulação só tem a acrescentar quando o vínculo transferencial que se cria é consistente, não só se fazendo notar como compreender.

Vale dizer, por fim, que a materialização do enquadre na cidade e a circunstância de um enquadre em movimento, se por um lado não é suficiente para produzir efeitos terapêuticos, também, por si só, não coloca o terapeuta em uma situação de desproteção e vulnerabilidade. O que faz valer o caráter terapêutico do acompanhamento é o vínculo, e ele se faz com tato, espera e sustentação de um enigma. Se este enigma é presente em uma andança desnorteada pela USP, quem lhe trará uma direção é o paciente. A partir disso é que se pode criar meios para avançar no tratamento em AT: contar com as direções e não-direções colocadas pelo paciente nas diversas situações que se esboçam. Toda uma reflexão sobre a função do enquadre mostra-se, assim, adequada e importante para que se avance pensando sobre este importante dispositivo de tratamento. 
CONSIDERATIONS ABOUT THE SETTING IN THE THERAPEUTIC ACCOMPANIMENT CLINIC

\section{Abstract}

This article discusses questions related to the flexibility of the setting in the Therapeutic Accompaniment. For reaching this objective, it brings a revue of the analytic technique for Frend, in what refers to the psychoanalytic abstinence; and Ferencis, in what refers to the technique's elasticity. It also discusses the elements of the setting for some psychoanalyst's posFreudians to reach, finally, a narrative of a clinical fragment from a meeting between the author and her patient. The revision and the narrative unfold a reflexion about the creation and management of a setting in the Therapeutic Accompaniment clinical modality.

Index terms: Psychoanalysis; Therapeutic Accompaniment; setting.

CONSIDERACIONES ACERCA DEL ENCUADRE EN LA CLINICA DEL ACOMPAÑ AMIENTO TERAPÉUTICO

\section{Resumen}

El artículo discute cuestiones relacionadas a la flexibilidad del encuadre (setting) en Acompañamiento Terapéutico (AT). Para tal, trae una revisión de la técnica analítica para Freud, en lo que se refiere a la abstinencia psicoanalitica y $\mathrm{Fe}$ renczi, en lo que se refiere a la elasticidad de la técnica. Discute lo que algunos psicoanalistas pos-freudianos entienden por encuadre analítico para llegar, en fin, a la narrativa de un fragmento clínico de un encuentro entre la autora y su paciente. Los desdoblamientos de la revisión y de la narrativa son los que profundizaran una reflexión sobre la creación y sustentación de un encuadre en la modalidad clinica del AT.

Palabras clave: Psicoanálisis; Acompañamiento Terapéutico (AT); encuadre.

\section{REFERÊNCIAS}

Berlinck, M. T. (2008). Psicopatologia fundamental. São Paulo: Escuta

Bleger, J. (1977). Simbiose e ambigüidade. Rio de Janeiro: Francisco Alves.

Coelho Junior, N. (2008). Psicanálise, corpo e setting. In L. C. Figueiredo \& N. Coelho Junior, Ética e técnica em psicanálise. São Paulo: Escuta.

De Deus, R. T. (2007). O psicótico e o seu ninho: um estudo clínico sobre o setting psicanalitico e os seus destino. Tese de Mestrado, Programa de Estudos Pós-graduados em Psicologia Clínica, Pontifícia Universidade Católica de São Paulo. São Paulo.

Fédida, P. (1988). Clinica psicanalitica: estudos. São Paulo: Escuta.

Fédida, P. (1991). Crise et contre-transfert. Paris: PUF.

Fédida, P. (1992). Nome, figura e memória: a linguagem na situação psicanalítica. São Paulo: Escuta.

Ferenczi, S. (1987). Prolongamentos da técnica ativa em Psicanálise. In S. Ferenczi, Escritos sobre técnica. (C. Berliner, trad., pp. 65-80). São Paulo: Escuta. (Trabalho original publicado em 1921)

Ferenczi, S. (1987b). Contra-indicações da técnica ativa. (Trabalho original publicado em 1926)

Ferenczi, S. (1987c). Elasticidade da técnica psicanalítica. (Trabalho original publicado em 1927)

Figueiredo, L. C. (2008). Presença, implicação e reserva. In L. C. Figueiredo \& N. Coelho Junior, Ética e técnica em psicanálise (pp. 13-54). São Paulo: Escuta.

Freud, S. (2006). Observações sobre o amor transferencial. In S. Freud, Edição standard brasileira das obras psicológicas completas de Sigmund Freud. (J. Salomão trad., Vol. 12, pp. 175-188). Rio de Janeiro: Imago (Trabalho original publicado em 1915)

Freud, S. (2006). Neurose e psicose. In S. Freud, Edição standard brasileira das obras psicológicas completas de Sigmund Freud. (J. Salomão trad., Vol. 19, pp. 167-171). (Trabalho original publicado em 1924) 


\section{Artigo}

Green, A. (2008). Orientações para uma psicanálise contemporânea. Rio de Janeiro: Imago.

Palombini, A. L. (2004). Um estilo próprio à clínica. In A. L. Palombini (Org.), AT na rede publica: a clinica em movimento (pp. 77-82). Porto Alegre: UFRGS.

\section{NOTAS}

1 Utilizaremos o original setting, pois a teorização sobre o enquadre foi feita pela primeira vez por $\mathrm{D}$. W. Winnicott. Será utilizado o termo enquadre quando o autor referido também o utilizar.

2 A dinâmica da transferência (1912), Observações sobre o amor transferencial (1915) Esboço da Psicanálise, escritos sobre técnica, cap. VI (1938).

3 Do gr. tële, «longe» +páthos, «emoção viva» +-ia 1. Capacidade que se pretende possuam algumas pessoas de transmitir e receber pensamentos a distância, sem que façam uso dos sentidos naturais. 2 Essa transmissão.

crisgerab@gmail.com mtberlin@uol.com.br

Recebido em março/ 2011.

Aceito em agosto/ 2011. 